\section{The future for Level 4 NVQs: a developmental approach?}

\author{
Nicholas Lewis
}

\author{
The Author \\ Nicholas Lewis is currently Liaison Librarian for Classics \\ and Modern Languages at Royal Holloway, University of \\ London. His first degree was in English \& Drama at \\ Bristol University and he subsequently studied for a \\ PGCE at Reading. He has worked in the public sector for \\ several years, during which time he has been involved in \\ NVQ delivery and the Investors in People initiative. In \\ 1999 he was awarded an MA in Information Management \\ from Thames Valley University. He can be contacted by e- \\ mail at n.lewis@rhbnc.ac.uk
}

\section{The Occasion}

Nicholas is this year's winner of the Group's Postgraduate Prize.

\begin{abstract}
An update on the development of Level 4 ILS NVQs since 1998 is outlined. The extent to which the revised standards will address the limitations of the original standards in terms of underpinning knowledge and higher level skills is discussed. The analysis takes into account research into Level 4 ILS NVQs since 1998 and updates the findings and recommendations of the original research paper. In particular, it argues that the future for these qualifications is dependent upon them being viewed as developmental rather than simply a measure of existing competence.
\end{abstract}

\section{Acknowledgements}

The author would like to thank Tony Olden, Senior Lecturer at Thames Valley University, for his continuing support during this research. Thanks are also due to John Hobson (Chief External Verifier for ILS NVQs), John Pluse (Director of the NTO) and Angela Frampton (NTO).

\section{Introduction}

Revised standards for the ILS NVQs were due in October 1998 but are now unlikely to be available before December of this year. The standards themselves have, by and large, been approved by the Qualifications \& Curriculum Authority (QCA) and a draft has been available from the Information Services National Training Organisation (isNTO) for several months. Their publication has been delayed for various reasons, most recently whilst an assessment strategy was being approved to go with the standards'. The advice for new candidates at the end of 1998 was to delay registration until the revised standards had been published. Unfortunately this wait of a couple of months has turned into two years and there is a danger that the momentum of these comparatively new qualifications will be lost. Whilst this is not so serious for Level 2 and 3 NVQs where there has been a much greater uptake overall. it could be a major blow to the success of the Level $4 \mathrm{NVQ}$ for which numbers have been much lower. Not surprisingly there has been no significant increase in new candidates since October 1998. The Chief External Verifier, John Hobson, recently confirmed that the delay was having a "major impact"- on the development of the qualifications in the sector. In particular, colleges are becoming increasingly wary of extending their Level 4 programmes as the numbers are not viable.

Despite this delay, there have also been some positive developments in the last couple of years. The revised standards for Level 4 ILS NVQs, once they are published, will be a significant improvement on the original ones. There are more detailed specifications for underpinning knowledge and a greater emphasis on reflection and evaluation. Furthermore, they are now overseen by the new isNTO which should promote the qualification more effectively as part of its broader brief of developing training in the sector as a whole.

So just how far have the standards moved on since the 1998 research which explored whether Level 4 NVQs should be seen as an alternative route to professional status in the sector? 
The future for Level 4 NVQs Nicholas Lewis

\section{The 1998 research}

In June 1998, seven of the thirty-nine candidates in the UK stated that they were doing the NVQ as an alternative to a Library/Information Studies degree or diploma. It was these candidates in particular who were concerned about parity of status with professional librarians once their qualification had been completed. The question was debated in the light of a review of the literature, a survey of Level 4 candidates, and interviews with a variety of practitioners, including managers, assessors and external verifiers closely involved in their delivery. Additional qualitative information was derived from four candidate case studies.

The benefits of the Level 4 ILS NVQs for individuals and their employers were identified, initially through the results of a questionnaire returned by 33 of the 39 candidates. These showed that the qualification required individuals to be carrying out a significant amount of what has traditionally been regarded as professional-level work, such as identifying and meeting user's complex information needs, ensuring quality standards in service delivery, and implementing change. Optional units covered stock selection and acquisition, abstracting and indexing, user education, staff training, recruitment and selection, and management activities. There was clear evidence that candidates had contributed to the improvement of working methods and systems in their workplaces, been involved in special projects and events, increased the profile of their role, and demonstrated their competence to their employers.

However, despite the benefits of the qualification, the research identified two key limitations of the Level 4 ILS NVQ in terms of underpinning knowledge and the demonstration of higher level skills. These were particularly marked when comparisons were made between the content and format of Level 4 ILS NVQs and the curricula of library schools.

The research showed that whilst NVQs at Level 4 did cover underpinning knowledge and understanding'; much of the knowledge evidence was limited to what was relevant to the candidate's specific work context. In the standards the specification of knowledge required was sketchy and there was a lack of guidance on how broader
Library \& Information Research News (LIRN)

Volume 24 - Number 77 - Summer 2000

knowledge might be obtained. In addition, the optional nature of many of the units meant that candidates could miss out on the full range of core topics such as Information Technology and Management - which are, by contrast, mandatory for library school courses.

The other main limitation was that the standards did not cover adequately the kind of higher level skills required by the library and information professional. Whilst the specialist and technical skills, such as handling enquiries, providing advice to users, and acquisitions, for example, were well covered, the more generic interpersonal and managerial skills were less in evidence.

Judith Elkin has identified some of these generic, rather than information-specific, skills that are the focus for assessment at library schools:

analytical thinking;

professional level report writing and presentation skills;

time management skills and the ability to work under pressure;

confidence and competence in using IT;

ability to work effectively in teams. ${ }^{5}$

Problem-solving, decision-making and evaluation skills could be added to this list. Although some of these were demonstrated by candidates in their choice of optional units, especially the ones imported from the Management NVQs, the structure of the qualification limited the number a candidate could take. Furthermore, as candidates did not always have an opportunity to gain the range of management experience required to complete such units successfully, there was a tendency to avoid them. For example, only six candidates chose the unit on solving problems and making decisions, and only three chose the unit on developing teams and individuals. This compared with larger numbers choosing the more technical units: 16 opted for the withdrawing unwanted material unit and 22 did at least one of the two acquisitions units. 
It was also debatable whether these higher level skills could be developed in isolation without at least some form of training or development activity to complement them. The survey results and case studies supported the view that doing an NVQ tends to be an isolated experience. By contrast, a library school qualification is done in a collective environment where learning takes place from others, The research concluded that, on its own, the Level 4 ILS NVQ was not enough to be seen as an alternative route to professional status in the sector. It made several recommendations for how this situation might change in the future. These included improvements to the revised standards,

specification of underpinning knowledge, and better links with library schools and the professional bodies. Above all, there was a need for a more integrated approach to education and training in the sector so that the role of the Level 4 ILS NVQ could be recognised, at least in part, as an alternative route to becoming a qualified librarian.

\section{The revised standards: underpinning knowledge}

Since the end of 1998 there have been some positive developments consistent with the recommendations made. The revised standards will have a greater emphasis on the importance of underpinning knowledge. There is clearer guidance for candidates and assessors as to what is required. This is explained in a separate 'Assessment Guidance' section:

"Along with each outcome [in each unit], there is a description of the knowledge each person should use if they are to perform competently. This is shown in the Knowledge Evidence section." 6

Additional notes explain how this section is set out:

"Knowledge is organised into different types, as follows:

- why you do things, or why certain things are important

- methods and techniques, or how to do things

- what facts and data you should know

- people who are important in achieving the outcome - who you should know"7
In comparison with the original standards, the specifications for each unit are more detailed, helping candidates to demonstrate a broader and more thorough knowledge of the main issues that underpin their work. As before, there are knowledge specifications for health and safety, equal opportunities and data protection - for example. The presentation and explanation of these requirements has improved - making it easier for candidates to understand how to demonstrate their knowledge. This change of presentation also helps to emphasise the importance of sector-wide as well as libraryspecific knowledge; for example, the 'Support and advise individual learners' unit requires candidates to demonstrate their knowledge of "what current national and organisational debates concern learning".

\section{The revised standards: higher level skills}

There is a more explicit emphasis on planning, negotiating and problem-solving in the revised standards, especially in the units imported from the Management NVQs. The most significant improvement in this respect is the new mandatory 'Develop your own resources' unit which encourages candidates to reflect upon and evaluate their own work and development. It has an emphasis on time and resource management, with opportunities to provide evidence of higher level skills.

The Assessment Guidance section also encourages candidates to look at "the possibilities of job rotation or work placement" if their workplace does not offer sufficient opportunities to meet the requirements of a particular unit. This should encourage candidates to choose more of the optional management units instead of the more limiting technical ones.

The revised standards seem to have closed the gap between the experience of doing a Level 4 ILS NVQ and a library school degree or post-graduate qualification. The question is whether this underpinning knowledge and these higher level skills can be demonstrated adequately through the NVQ without some form of education and training to complement them. 
The future for Level 4 NVQ Nicholas Lewis

Susan Hornby, lecturer at Manchester Metropolitan University, recently outlined the benefits of the library school approach to professional education as compared with the approach of higher level NVQs. Her research showed that library schools tend to share the view that "...a development of understanding and knowledge goes beyond a skillsbased approach to learning, and allows students to make connections, links and in some cases intuitive leaps that provide a 'reflective practitioner"'s. The argument is that by acquiring higher level competencies, primarily through a theoretical course, information professionals are able to "...move beyond the practice; they need to understand that competencies change over time...Future professionals need to be able to anticipate the direction of change and be prepared to alter practice accordingly." ${ }^{\text {"9 }}$ This argument is a sound one, but it is based on an underlying assumption that the NVQ curriculum does not allow for the demonstration of these higher level competencies at all, and this is clearly not the case.

The 1998 research found that several of the Level 4 ILS NVQ candidates were demonstrating higher level skills and providing some evidence of reflection and evaluation. The problem was that this level of engagement was dependent upon choosing the more challenging units, especially those from the Management section. Instead, many candidates opted for the technical ones, particularly those who felt they had few opportunities to demonstrate their higher level skills at work. As we have seen, though, this limitation has been addressed by the improvements to the content and structure of the revised standards. Indeed, it could be argued that these skills are more likely to be developed in the workplace where time constraints and the pace of change will have a more immediate impact than case studies or simulations being used in library schools.

So the argument that an understanding of the theories and concepts that underpin professional level work cannot be obtained on the job but only in an academic environment does not stand up to close scrutiny. If it were true, then the whole notion of Continuing Professional Development, which involves learning in the workplace, would be undermined. The view excludes the idea of personal development through networking, learning from experience and learning from other colleagues,
Library \& Information Research News (LIRN)

Volume 24 - Number 77 - Summer 2000

which should be an integral part of the working experience for individuals at this level.

Having said that, it is important that the Level 4 ILS NVQ candidates make choices that enable them to demonstrate these higher level skills. They need to show that they have covered the breadth, as well as the depth, of the topic areas they have chosen. Is there sufficient evidence of reflection on issues across the sector as a whole, such as copyright for example, rather than simply an analysis of the law as it affects the information centre the candidate is working in? It is unlikely that many candidates would be able to demonstrate this breadth without at least some form of additional education or training.

\section{Complementary education and training}

Purists would argue that the NVQs should have nothing to do with education and training. But there can be little doubt that anyone doing the Level 4 ILS NVQ would benefit from some of the learning experiences that are available through the library school courses, for example working in teams, problem-solving, critical analysis, etc., just as any library school student would benefit from the practical rigour of the NVQ.

There is evidence that more integrated approaches to learning are beginning to take place in the sector. Most notably, the University of Northumbria at Newcastle has recently permitted a successful Level 4 ILS NVQ candidate to have exemption from the first two years of the undergraduate Information Management qualification ${ }^{10}$. This recognises that some form of learning, education and development has taken place in carrying out this Level 4 ILS NVQ within the workplace. This should open the door for other candidates to apply and is a challenge to other library schools to review their admissions criteria.

Research sponsored by the Library and Information Commission in 1999 has also emphasised the importance of a developmental approach to the delivery of ILS NVQs. The INSIST project identified two basic approaches to these NVQs - the mechanistic and the holistic. The former involved taking candidates "en bloc" and covering "identical units over the same time period." The latter involved "...integrating NVQs with other teaching and training activities; and involving other staff in the 
delivery." ${ }^{11}$ The holistic approach is seen as the most likely to lead to success and the use of complementary learning and training was seen as an integral part of this. Similarly, the 1998 research found that those who saw the Level 4 ILS NVQ as developmental were most successful at getting through the workload and keeping motivated.

So, whilst the Level 4 NVQs are designed to be a measure of competence in the workplace, they can also be used developmentally. To achieve this, some complementary education and/or training may well be necessary, although it need not necessarily be on the scale of the Newcastle example. There should be some flexibility in terms of how this is attained, especially in areas where access to a library school or college is difficult. There is a role for training providers here too, such as FE colleges and the Library Association, although in many cases the fees for courses remain too high to make this viable for many candidates. However, there are many professional groups and associations within the sector that could perhaps be involved in providing a context for this kind of learning.

\section{Developmental approaches to NVQs}

The main flaw of the higher level NVQ qualifications has been the insistence that they should be seen as just a measure of existing competence - the ability to carry out one's job in the workplace - rather than as a developmental tool. If the NVQ is seen as only an acknowledgement of existing competence then it is not surprising that candidates ask 'what's the point?'. If a candidate has got to this level, in a role which includes a wide range of professional tasks, they are likely to be viewing their job as a career. Anything they choose to do as a qualification is likely to be to develop that career further.

To take the argument a step further, if these NVQs are not developmental, what is the benefit for the manager of the service or the library as a whole? Is it worth investing time and resources into NVQs just to prove that the workforce can stand still? If this is the approach taken, where is the ability to respond to change, to learn from experience and to move beyond existing competencies? By retaining the rigid view of NVQs as simply measuring existing competence, the argument with the library schools is lost and they exploit this flaw for all its worth:
"NVQs are not concerned with education; they are about collecting evidence to prove competence." ${ }^{12}$

There should be no problem with ILS NVQs at this level fulfilling both aims: acting as measure of existing competence as well as a springboard for further learning and development. For the most successful candidates, this is what already happens in practice. They take on new projects, wider responsibilities and new areas of work in order to cover the range of units. If NVQs are carried out in this way, they can be developmental. Conversely, if they are carried out using existing work, with little support from managers, and if a narrow range of units is chosen, then their benefits are clearly limited.

If $N V Q$ s are to survive at Level 4, then they have to be embraced as qualifications that are challenging developmentally, not simply in terms of their administrative workload. The qualification should excite attitudes of enthusiasm and motivation rather than ones of indifference and apathy. There is clearly a role for NVQ practitioners here, as mentors, assessors and verifiers, to ensure that the NVQ is approached in this way and that its full potential is realised. If this happens, far more candidates will be in a position to justify their qualification as a suitable route to professional status.

\section{Access to Associateship}

Provided that there is clear evidence of knowledge and the development of higher level skills, along with an assessment of the learning that has underpinned this, then there is no reason why successful candidates should not take their development further by applying for the Library Association's Associateship (Chartership) scheme. This aims to develop further the notion of the reflective practitioner. The guidelines for producing a Professional Development Report or Portfolio require such skills to be demonstrated both implicitly - in the discipline of writing reflective and evaluative reports - and explicitly in the presentation of evidence of professional work in the content of the report / portfolio. Candidates must demonstrate how their theoretical understanding of professional issues has been applied in practice. 
The future for Level 4 NVQs

Nicholas Lewis

Currently candidates without a relevant degree and/or postgraduate qualification accredited by the Library Association are not permitted to apply for this scheme. But it could be argued that if a qualified Level 4 candidate is prepared to put themselves through the rigour of the Associateship Scheme, it might be better to encourage their application rather than assuming that the experience of doing a Level 4 is inadequate in comparison with the accredited qualifications. If a candidate's knowledge and higher level skills are lacking, this should become evident in the Associateship assessment process which acts as another quality check on the route to full professional status. Opening this alternative route would remove the barrier to some very competent paraprofessionals gaining professional status. The concern that this would open the floodgates to entrants via this route is not well founded. After all, the rigour of a Level 4 ILS NVQ should not be underestimated and, indeed, it takes longer to complete than a postgraduate Diploma, for example.

However, successful Level 4 candidates without degrees are unlikely to be allowed to apply for the Associateship Scheme in the near future. The number of Level 4 ILS candidates remains too small to have a significant voice in the profession. In the meantime, the Library Association stands its ground by waiting for decisions about Level 4 equivalencies to be made in other sectors.

There are some positive signs for the future, though, with the creation of the new Information Services National Training Organisation (isNTO). As well as overseeing the future development of the NVQs, one of its objectives is to investigate equivalencies:

"There will be a project on relationships between qualifications in the sector, and routes for individuals to take between them."13. The appointment of Sheila Corrall, the Reading University Librarian, as Chairperson of the isNTO, should help to open up a more productive dialogue with the library schools and the Library Association. Her extensive knowledge of the HE sector and her many publications on the role of the Information Professional should help to facilitate a more constructive discussion about the status of the higher level NVQs in the sector.

\section{Conclusion}

In summary, the revised standards place a much greater emphasis on demonstration of underpinning knowledge and higher level skills. When the isNTO markets these new standards, it will be important to highlight these changes. The Level 4 ILS NVQ should be marketed as developmental rather than simply a measure of existing competence. However, the current delay in publishing the revised standards may make this difficult to achieve. Considerable work will need to be done to persuade candidates, and assessment centres, that the Level 4 ILS NVQ is a worthwhile investment.

Susan Hornby's research concluded that ". . .NVQs and $\mathrm{HE}$... each have a role to play in the training and development of information professionals but their roles are distinct and separate." ${ }^{1+}$ This paper has argued that, on the contrary, there is considerable overlap and that there needs to be greater integration of approach. The Level 4 ILS NVQ, if done in a way which is developmental and demonstrates underpinning knowledge and higher level skills, should act as an alternative route for those who, for legitimate reasons, cannot afford to take time out for study at library school. These include paraprofessionals with many years of experience, those with family commitments, and those whose workplace will not release them for further study. The argument here is not against the many benefits of the library school courses, but against the assumption that their students will necessarily be better placed than Level 4 NVQ candidates to attain professional status in the Library and Information sector. 


\section{References}

OCR [telephone call] (4th April 2000)

2John Hobson, Chief External Verifier, telephone

interview with Nicholas Lewis on 17th February 2000

${ }^{3}$ Nicholas Lewis, Level 4 Information and Library Services

NVQs: an alternative route to professional status in the ILS

Sector? [MA Thesis] (London:Thames Valley University,

1998). See also: Nicholas Lewis, 'Level 4 NVQs: an

alternative route to professional status?' Library

Association Record 101 (2) (1999), p. 94-6.

${ }^{4}$ the term 'understanding' referring to the practical application of that knowledge

5udith Elkin, 'The Role of LIS Schools and Departments in Continuing Professional Development' Librarian Career Development, 2:4 (1994), 19-23, p. 22.

${ }^{6}$ Information \& Library Services Level 4: Revised

Qualification Structure and National Occupational Standards, 1998 [Draft revised standards].

${ }^{7}$ ibid.

${ }^{8}$ Susan Hornby, 'The compatibility between Higher Education aims and objectives and Level 5 NVQs:The case for information management' [Conference paper] (October 1999) http://conference99.fh-

hannover.de/fulltext/hornby_f.htm (Accessed: 4th April 2000).

9 ibid.

${ }^{10}$ Sandra Parker et al., INSIST: The impact of NVQs in Information and Library Services on Staff Induction and Staff Training (Library and Information Commission, 1999), p. 79.

"ibid., p. 83

${ }^{12}$ Hornby, op. cit.

${ }^{13}$ John Pluse, Director of the isNTO; statement made at PTEG Event 'An Evening with the is NTO', 24th February 2000

${ }^{14}$ Hornby, op. cit. 